\title{
Antifungal Resistance in Candida auris: Molecular Determinants
}

\author{
María Guadalupe Frías-De-León ${ }^{1}$ (D), Rigoberto Hernández-Castro ${ }^{2}$, Tania Vite-Garín ${ }^{3}$, \\ Roberto Arenas ${ }^{4}\left(\mathbb{D}\right.$, Alexandro Bonifaz ${ }^{5}$, Laura Castañón-Olivares ${ }^{3}$, \\ Gustavo Acosta-Altamirano ${ }^{1}$ and Erick Martínez-Herrera ${ }^{1, * \mathbb{D}}$ \\ 1 Unidad de Investigación, Hospital Regional de Alta Especialidad de Ixtapaluca, Estado de México, \\ 56530 Mexico City, Mexico; magpefrias@gmail.com (M.G.F.-D.-L.); mq9903@live.com.mx (G.A.-A.) \\ 2 Departamento de Ecología de Agentes Patógenos, Hospital General “Dr. Manuel Gea González”, \\ Ciudad de México, 14080 Mexico City, Mexico; rigo37@gmail.com \\ 3 Unidad de Micología, Facultad de Medicina, Universidad Nacional Autónoma de México, \\ 04510 Mexico City, Mexico; tania.vite.garin@gmail.com (T.V.-G.); lrcastao@unam.mx (L.C.-O.) \\ 4 Sección de Micología, Hospital General “Dr. Manuel Gea González”, Ciudad de México, \\ 14080 Mexico City, Mexico; rarenas98@hotmail.com \\ 5 Departamento de Micología, Servicio de Dermatología, Hospital General “Dr. Eduardo Liceaga”, \\ Ciudad de México, 06720 Mexico City, Mexico; a_bonifaz@yahoo.com.mx \\ * Correspondence: erickmartinez_69@hotmail.com
}

Received: 7 August 2020; Accepted: 29 August 2020; Published: 2 September 2020

\begin{abstract}
Since Candida auris integrates strains resistant to multiple antifungals, research has been conducted focused on knowing which molecular mechanisms are involved. This review aims to summarize the results obtained in some of these studies. A search was carried out by consulting websites and online databases. The analysis indicates that most $C$. auris strains show higher resistance to fluconazole, followed by amphotericin B, and less resistance to 5-fluorocytosine and caspofungin. In C. auris, antifungal resistance to amphotericin $B$ has been linked to an overexpression of several mutated ERG genes that lead to reduced ergosterol levels; fluconazole resistance is mostly explained by mutations identified in the ERG11 gene, as well as a higher number of copies of this gene and the overexpression of efflux pumps. For 5-fluorocytosine, it is hypothesized that the resistance is due to mutations in the FCY2, FCY1, and FUR1 genes. Resistance to caspofungin has been associated with a mutation in the FKS1 gene. Finally, resistance to each antifungal is closely related to the type of clade to which the strain belongs.
\end{abstract}

Keywords: antifungal resistance; Candida auris; amphotericin B; 5-fluorocytosine; caspofungin; fluconazole

\section{Introduction}

Candida auris is characterized for being a critical pathogen worldwide that has resistance to virtually all antifungals commonly used in the treatment of invasive fungal infections. C. auris poses a severe threat to human health due to the increase in the frequency with which it occurs, mainly in Intensive Care Unit patients, where life-threatening candidiasis outbreaks have occurred. In some countries, this is being considered as a serious public health problem [1-3].

Since it was discovered in 2009, C. auris has spread very quickly. The first isolates came from Japan, India, Pakistan, South Africa, and Venezuela, but currently, its presence has been recorded in 19 other countries of the six continents $[2,4,5]$.

Phylogenetic studies carried out in genomes of various C. auris [6-8] isolates have identified four predominant populations (clades I, II, III, and IV). The evidence of a smaller population, related to an 
isolate cultivated from the otic exudate of an Iranian girl, has probably identified a clade V [9]. While clades I to IV have persistently shown a wide geographical distribution, not many isolations have been obtained from the population of clade V [5].

The territorial expansion of the yeast, among other explanations, is because this organism has been identified incorrectly as C. haemulonii, C. famata, C. catenulata, or even Rhodotorula glutinis through phenotypic characterization techniques. This situation has favored the delay of preventive measures for contagion and dissemination or prevents them from being taken [3].

C. auris multi-resistance can be attributed to its phylogenetic relationship with other Candida species that are inherently resistant to more than one antifungal [3,5].

There are mainly three classes of antifungals for systemic use: azoles, polyenes, and echinocandins. It has been published that more than $90 \%$ of the C. auris isolates are resistant to fluconazole (azole), although resistance levels vary considerably between clades. Minimum inhibitory concentrations (MIC) that are high to amphotericin B (polyene) have been reported in several studies, and resistance to echinocandins is emerging in the isolates of some countries [10].

High rates of antifungal resistance in clade I have been observed, including four isolates resistant to the three main antifungal classes [5].

It has been reported that $Y 132 F$ mutations in ERG11 associated with azole resistance and S639P in FKS1 for echinocandin resistance vary between clades. The copy number variations in ERG11 predominate in clade III and have been associated with resistance to fluconazole [5].

It is essential to know the ways by which this organism presents its multi-resistance to improve health and control measures caused by $C$. auris infection.

The increase in the prevalence of multidrug-resistant C. auris to different groups of antifungals is a cause for alarm, especially considering that there are few treatment options nowadays. The latter has prompted the search for other therapeutic alternatives such as natural peptides, phenolic compounds, nitric oxide nanoparticles, as well as miltefosine and iodoquinol [11-17]. The conducted researches are promising, as they show that several of these alternatives can be used alone or in combination with other traditional antifungals, which produces a synergistic effect that potentiates fungal destruction.

\section{Materials and Methods}

The objective of this review is to provide recent information on the fundamental studies that explain from a molecular standpoint, the multi-resistance to antifungals that identifies most $C$. auris strains. To achieve this goal, the method used was a search that included the Science Direct website and the Springer Link, Wiley Online Library, and Medline (Pubmed) databases was performed, using as keywords: Candida auris antifungal resistance. The search yielded 4518 publications, of which 4415 were discarded for not meeting the subject or being in languages difficult to translate. Finally, only 102 articles were used, which were included in the 2000-2020 period, however, one article from 1994 was included due to its historical relevance. The review was performed based on PRISMA (Preferred Reporting Items for Systematic Reviews and Meta-Analysis) (Figure 1). 


\section{PRISMA 2009 Flow Diagram}
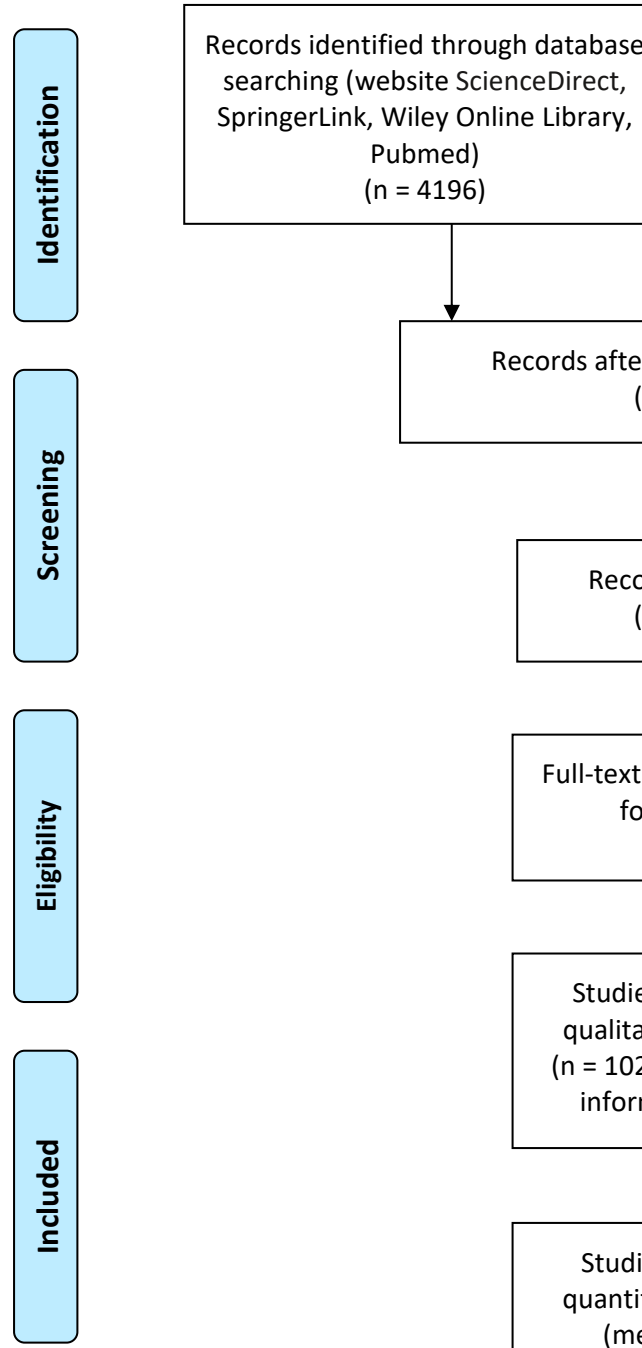

Additional records identified through other sources $(n=322)$

Records after duplicates removed $(n=3162)$

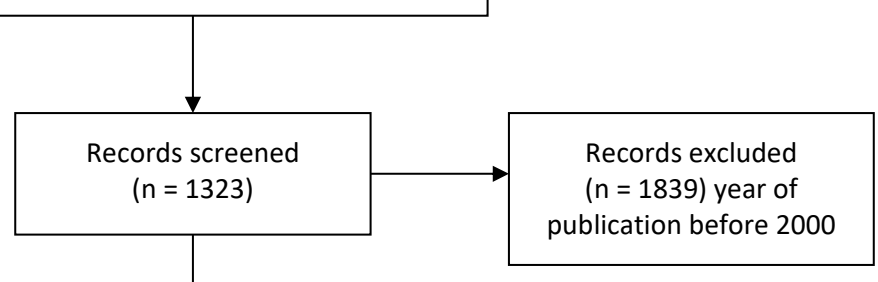

Full-text articles assessed for eligibility $(n=812)$

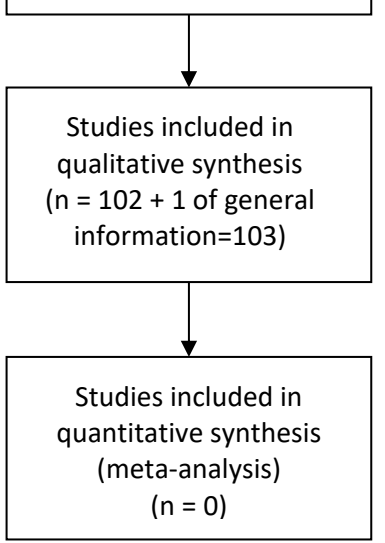

Full-text articles excluded, with reasons $(n=710)$

- Referred to another species of Candida

- Language difficult to translate

- They did not mention pharmacological resistance or molecular aspects

- Mention nonpharmacological therapies

Figure 1. Flowchart of the different phases of the systematic review.

\section{Polyenes}

The drugs belonging to this group of antifungals are amphotericin B (AMB), nystatin, and natamycin. The latter acts in a different way from the AMB and the nystatin, as it interacts with ergosterol without forming ion channels; however, it can alter ergosterol-dependent reactions that precede the fusion of cell membranes [18].

Antifungal resistance to polyene is often rare in other Candida spp. species. (except C. lusitaniae) [19-21], but it can be generated through prophylactic or therapeutic exposure. Besides, it has been theorized that prior treatment with azoles decreases ergosterol concentrations resulting in subsequent resistance to polyenes $[19,22,23]$. Some studies show the complete sequencing of the C. auris genome, where three different amino acid substitutions have been observed in the ERG11 gene related to different geographic clades (F126T, Y132F, K143F). Such mutations are associated with isolations in different continents; therefore, it can be inferred that the antifungal resistance that $C$. auris possesses can be acquired rather than being intrinsic [2,21,24,25]. 
Regarding the antifungal susceptibility of $C$. auris to polyenes, especially AMB, there are variable results according to different studies conducted in recent years; however, in most of them, it occupies the second place of resistance after fluconazole. Calvo et al., 2016 showed the in vitro susceptibility of 18 C. auris isolates with MIC50 of $1 \mathrm{mg} / \mathrm{L}$ and MIC 90 of $2 \mathrm{mg} / \mathrm{L}$, resulting in low susceptibility to AMB by having $50 \%$ of strains with elevated MICs [4].

It is suggested that between 10 and $35 \%$ of $C$. auris isolates are AMB resistant; for example, in the US, a study conducted by Ostrowsky et al., 2020 reported that nearly two-thirds of the studied isolates were resistant. On the other hand, in a study made by Vallabhareny et al., 2017, only one isolated of 7 was resistant [26-28]. In the systematic review of Osei Sekyere, 2018, 15.46\% of the C. auris sample showed AMB resistance [29]. Arendrup et al., 2017, for their part, obtained that using the cut-off points given by the $\mathrm{CDC}$, out of $742 \mathrm{C}$. auris isolates 111 were $\mathrm{AMB}$ resistant, corresponding to $15.46 \%$ which coincides with Osei Sekyere's study [30]. In Kuwait, Khan et al., 2018 found that from a sample of 56 isolates, 13 were resistant to $\mathrm{AMB}$ and 11 to fluconazole, voriconazole, and AMB. However, there are no clinical cut-off points available for $C$. auris. Hence, if another MIC reference were considered for $\mathrm{AMB}$, the resistance in this study would have increased significantly to $29(52 \%)$ [31]. On the other hand, Lockhart et al., 2017 observed that out of 54 isolates, 19 were resistant to AMB, which represents $35 \%$ [6]. C. auris is therefore highly resistant to azoles and polyenes, which can be attributed to its phylogenetic relationship with other of Candida spp. species that are inherently resistant to multiple antifungals $[6,29]$.

C. haemulonii, C. duobushaemulonii, and C. pseudohaemulonii may exhibit high-grade intrinsic resistance to $\mathrm{AMB}$ with MIC that can reach up to $16 \mathrm{mg} / \mathrm{L}$ [32]. Cases of acquired resistance to this group of antifungals have been reported in strains of C. albicans, C. glabrata, C. rugosa, C. lusitaniae, and C. tropicalis; as well as some cases of high MIC, poor response to treatment or even both in some strains of $C$. albicans, C. krusei, C. rugosa, C. lusitaniae, and C. glabrata as well as pan-resistant C. auris strains [22].

The molecular mechanism by which $C$. auris presents resistance to AMB is still unclear [1,33]. However, due to the mechanism of action of polyenes, alterations in the ergosterol pathway are considered the main resistance mechanism [10], which is related to ERG2, ERG3, and ERG6 gene mutation [1,30,34-37]. It is possible that mutations can cause depletion and alteration of the ergosterol composition [36]. In in vitro studies with $C$. albicans and C. glabrata strains, mutations that disrupt these genes have been observed. In studies made with isolated AMB-resistant $C$. auris strains compared to susceptible strains, overexpression of the ERG1, ERG2, ERG3, EGR5, ERG6, and ERG13 genes was observed [32,38]. Mutations in these genes lead to reduced ergosterol levels in the plasma membrane, and thus, with the decreased levels, the AMB resistance increases $[20,23,28]$. At the same time, there are also other studies such as the one from Muñoz et al., 2018 that contribute to the idea that antifungal resistance is rather given at the transcriptional level $[39,40]$.

The study conducted by Muñoz et al., 2018 demonstrated that in C. auris, there is an intrinsic transcription of multidrug transporters higher than in other strains isolated from the study. After administrating $A M B$ to one of the $C$. auris strains, five genes that are involved in the ergosterol biosynthesis path (MVD,ERG2, ERG1,ERG6, and ERG13) were induced. These genes are associated with the maintenance of the fungus cell membrane stability, similar to the transcriptional response occurring in C. albicans. Two strains of a clade had different resistance phenotypes than AMB, and, by further analyzing them, the induction of 8 genes that were positively regulated was achieved in both strains, including OPT1, CSA1, MET15, and ARG1 [39]. Before polyene administration, one of the strains showed greater expression of genes involved in the transcriptional response of $C$. albicans to AMB, even when absent [39] (Table A1 in Appendix A).

A higher transcription of $C D R 4 a$ was observed, suggesting that a greater intrinsic expression of multidrug transporters is a possible antifungal resistance mechanism in C. auris [39].

In an effort to understand how the molecular resistance mechanism to AMB is generated, Escandón et al., 2018 identified a single nucleotide polymorphism (SNPs) in a transcription factor, similar to that of $C$. albicans, called FLO8 in an anonymous protein that supposedly encodes for a membrane 
transporter in AMB-resistant C. auris strains [32,41]. Escandón et al., 2019 were able to identify five non-synonymous mutations in protein-coding regions associated with AMB resistance in Colombian C. auris strains. Four mutations were found within the regions that encode for proteins, and one of them was the mutation in FLO8, a transcription factor required for virulence and formation of biofilms in C. albicans, which showed a change from a serine (in susceptible strains) to aspargine (in resistant strains). However, apparently, this mutation only represented a single event. No subsequent mutations occurred, and it has not been reported in the strains of C. auris 6684, B11220, B8441 from India, Japan, and Pakistan, respectively, and which are AMB-resistant [7,40,42]. Another mutation was found in a transmembrane protein that changes isoleucine to threonine, which could also contribute to antifungal resistance [7] (Table A1).

Thanks to the study of the C. auris genome, orthologous of virulence factors involved in the formation of biofilms, antifungal resistance, and phenotypic change have been identified, which are already known in C. albicans [1,20,24,29]. The formation of biofilms is especially suggested to have an important role in antifungal resistance in C. auris, including resistance to AMB, due to the possibility of being housed in this treatment-resistant cells which reduce drugs bioavailability $[1,29,36,43,44]$. Muñoz et al., 2018 showed in their study that SIT1, PGA7, and RBT5 are positively regulated during the formation of biofilms in C. auris, thus suggesting that cell wall reorganization could be a response to antifungal treatment [39]. Sherry et al., 2017 showed that biofilms were resistant to doses $>4 \mathrm{mg} / \mathrm{L}$ of AMB and that only liposomal AMB was effective in limiting the growth at a lower concentration (0.25-1 mg/L); however, $16 \mathrm{mg} / \mathrm{L}$ were needed to stop biofilm activity at $90 \%$ [45].

Thanks to different studies, ABC and MFS type efflux pumps are considered to be involved in the antifungal resistance of $C$. auris [7,24,43,46,47]. Studies conducted by Ben-Ami et al., 2017 demonstrated through the use of rhodamine that $C$. auris had greater activity in ABC-type efflux pumps than other species such as C. glabrata and C. haemulonii, which can be associated with its participation as an antifungal resistance mechanism [46]. The latter coincides with research conducted by Chatterjee et al., 2015. They identified orthologous genes from ABC and MFS-type efflux pumps, which they consider to be a possible antifungal resistance mechanism to azoles, polyenes, and echinocandins [24] (Table A1).

Bhattacharya et al., 2020 propose replicative aging as another antifungal resistance mechanism in C. auris, as it origins stem cells and daughter cells that are phenotypically different, where old cells become more tolerant to AMB [34,44].

In the search for new treatment therapies for infections generated by $C$. auris, combined therapy of antifungals with essential oils has been proposed as phenolic compounds have been observed to present synergistic antifungal activity with antifungals, decreasing their MIC [17].

\section{Triazoles}

Triazoles are part of antifungal treatment against infections caused by various species of Candida due to their effectiveness against the formation of the fungal plasma membrane. However, their extensive use causes side effects in the host and resistance in the pathogen [48-53].

According to Lockhart, 2019, the main resistance mechanisms to triazoles exhibited by C. auris strains are (1) Mutations in the antifungal target, mainly in the ERG11 gene, (2) Overregulation of ERG11, (3) Overregulation of efflux pumps. Likewise, this resistance is mostly towards fluconazole and less frequent towards other antifungals such as voriconazole, being that, from the evolution standpoint, it is a characteristic that arises on four occasions at least, so it is suggested that this process occurs due to the pressure exerted by the constant use of antifungals as a prophylactic method and for the treatment of nosocomial infections. This situation seems to be reinforced by the fact that fluconazole is the antifungal that is always available, which induces rapid mutations [6,32,54] (Table A1).

One of the most studied genes to understand the resistance of $C$. auris to antifungals is ERG11, which encodes for lanosterol-14 $\alpha$-demethylase (target protein of the fungistatic action of the triazoles) [26].

To the present date, 12 mutations have been identified in the ERG11 gene, which are possibly determined by geographical area [6] and which decrease the affinity of a triazole with the target while 
reducing the susceptibility of the fungus to the drug. The latter also generates different susceptibility patterns to the triazoles depending on the strain's place of origin $[19,32,39,54,55]$.

In addition to mutations, overregulation of the gene may occur in azole-resistant strains, as some genomics and transcriptomic studies have observed an increase in EGR11 transcripts, which may also be associated with cell age. However, this aspect has not been thoroughly studied yet $[32,56]$.

Fungi, like other microorganisms, present groups of transport proteins called efflux pumps, which allow them to prevent the accumulation of high antifungals concentrations, thus decreasing their effectiveness. The most studied efflux pumps in C. auris are those that function based on transport proteins from the ABC (ATP Binding Cassette) and MFS (Major Facilitator Superfamily) families, which are determined by the expression of the CDR1 gene [19,32,57].

In multi-resistant $C$. auris strains, it has been observed that $A B C$ transport proteins are represented in a significant portion of the genome. Also, it has been seen that in the presence of fluconazole, a greater expression of $C D R 1$ occurs. Among the performed analyses, resistant strains that had the gene deleted were studied. The Minimum Inhibitory Concentration (MIC) of fluconazole and itraconazole decreased, so it is suggested that this is one of the mechanisms for triazole resistance $[24,32,55,57,58]$ (Table A1).

Other resistance mechanisms that have been explored in recent years are related to the HSP90 protein and chromosome duplication. However, both require further studies for full understanding.

The HSP90 thermal shock protein is involved in the morphological changes of the fungus, suppressing the passage from the levaduriform phase to the filamentous phase of several species of Candida, especially C. albicans and C. auris. Kim et al., 2019, note that, in addition, this protein promotes resistance to triazoles by enabling key cellular responses that stabilize the cellular response to antifungal induced stress, since inhibition of the expression of this protein reduces the tolerance of the strain to fluconazole, by allowing its action to transform from fungistatic to fungicide, decreasing the survival of the fungus. However, few studies have been conducted on this subject [59] (Table A1).

Another mechanism of resistance to the triazoles is the duplication of the chromosome on which the ERG11 gene is located. However, the correct functioning of this process must still be determined $[32,56]$. This mechanism was observed only in stem cells that subsequently divide, and then it disappears into the daughter cells [56].

\section{5-Fluorocytosine}

The treatment of infections caused by different Candida species with 5-FC has shown effectiveness, except in C. glabrata and C. krusei [60]; however, in C. auris data is scarce and variable. Schelenz et al., 2016 reported that 15 clinical and environmental isolates from a C. auris outbreak that occurred at a cardio-thoracic centre in London, were susceptible to 5-FC (MIC $<0.06-0.12 \mathrm{mg} / \mathrm{L}$ ) [61]. In the same way, Lockhart et al., 2017 assessed susceptibility to antifungals in 54 C. auris isolates and found susceptibility with MIC values in the range of $0.125-0.5 \mathrm{mg} / \mathrm{L}[62,63]$. On the other hand, Chowdhary et al., 2014 reported $47 \%$ resistance to $5-\mathrm{FC}$ (MIC $\geq 64 \mathrm{mg} / \mathrm{L}$ ) in 15 C. auris clinical isolates, while Kathuria et al., 2015 found that out of 90 C. auris isolates that were analyzed, $12 \%$ showed resistance to 5-FC with MIC ( $\geq 32 \mathrm{mg} / \mathrm{L}$ ) and $88 \%$ showed MIC susceptibility $(0.4 \mathrm{mg} / \mathrm{L})[60,62]$. Ben-Ami et al., 2017 analyzed six C. auris isolates, of which five reported susceptibility to $5-\mathrm{FC}(0.25-0.5 \mathrm{mg} / \mathrm{L})$ and one not susceptible (1 mg/L) [46]. Osei Sekyere, 2018 calculated the overall resistance rate to 5-FC from reports of 742 clinical isolates of $C$. auris in 16 countries, mainly India, the United States and the United Kingdom, which resulted in 1.95\%, with MIC values between 1-128 mg/L [29]. Recently, O'Brien et al., 2020 analyzed 277 C. auris clinical isolates, finding a low ratio $(0.7 \%)$ isolates resistant to 5-FC (MIC $\geq$ $32 \mathrm{mg} / \mathrm{L}$ ) [64]. Based on these reports, it can be said that 5-FC is very active against C. auris, but it is clear that the risk of the yeast developing resistance persists.

It has been reported that fungal cells may develop resistance to 5-FC as a result of mutations that occur mainly in genes involved in the absorption and metabolism of 5-FC: FCY2, which encodes the purine-cytosine permease; FCY1, which encodes the cytosine deaminase, and FUR1 encoding the uracil 
phosphoribosyl transferase $[44,65]$. Resistance can be primary when related to a decrease in drug absorption by mutations in the gene $F C Y 2$, and secondary when there is a limitation in the conversion of 5FC into 5FU, or 5-fluorouridine monophosphate (5-FUMP) by alterations in FCY1 and FUR1 genes respectively [66]. In C. auris, there is no information regarding 5-FC resistance mechanisms; there is only one report of an isolate with the F211I mutation in an isolate that reported high MIC values in vitro, this mutation causes the substitution of isoleucine to phenylalanine [8] (Table A1). Although no further studies have been conducted to correlate the mutation with resistance to 5-FC, this is very likely a pathway through which $C$. auris acquired resistance to the antifungal, since mutations have been identified as an important resistance mechanism to 5FC in C. albicans, and C. lusitaniae with whom it has a close phylogenetic relationship [67-69]. Dogson et al., 2004 determined that a single change of nucleotide, from cytosine to thymine at position 301 of the FUR1 gene, which results in a change from arginine to cysteine at position 101 of the amino acid chain, is the most important mechanism of resistance to 5-FC, since yeasts with this mutation had VALUES of ICM $16 \mathrm{mg} / \mathrm{mL}$ to 5 -FC [68].

Papon et al., 2007 analyzed the inactivation of genes FCY2, FCY1 and FUR1 in C. lusitaniae and found that mutations in FUR1 generate resistance to 5-FU with high MIC values of ( $\geq 512 \mathrm{mg} / \mathrm{L}$ ), while mutations in $F C Y 1$ or $F C Y 2$ confer cross-resistance to 5-FC and FLC, with a lower resistance level to 5-FC (MIC $=64-128 \mathrm{mg} / \mathrm{L})$ compared to FUR1 inactivation [69].

To minimize the risk of therapeutic failure caused by the ability with which fungi develop resistance to $5-\mathrm{FC}$, it is recommended to use this drug in combinations with other classes of antifungals instead of monotherapy, as this has shown to promote a synergistic interaction between molecules [70]. Zhu et al., 2020 reported that combinations of 5-FC with other antifungals are successful in treating C. auris infections: for nine C. auris isolates resistant to $\mathrm{AMB}(>2.0)$, the combination of AMB/5-FC $(0.25 / 1.0124$ $\mathrm{mg} / \mathrm{L}$ ) produced $100 \%$ inhibition. Six C. auris isolates resistant to three echinocandins ([AFG $>4.0 \mathrm{mg} / \mathrm{L}]$, [CAS > $2.0 \mathrm{mg} / \mathrm{L}]$, [MFG $>4.0 \mathrm{mg} / \mathrm{L}])$, were $100 \%$ inhibited by the AFG/5-FC and CAS/5-FC $(0.0078 / 1$ $\mathrm{mg} / \mathrm{L})$ combinations, and MFG/5-FC (0.12/1 mg/L). Thirteen isolates with high MIC values for VRC (MIC $>2 \mathrm{mg} / \mathrm{L})$ were $100 \%$ inhibited when the combination VRC/5FC $(0.015 / 1 \mathrm{mg} / \mathrm{L})$ was used [71].

\section{Echinocandins}

Echinocandins are synthetically modified lipopeptides that uncompetitive inhibit the $\beta-1,3-\mathrm{D}-$ glucan synthase, which is the enzyme responsible for the biosynthesis of the main structural element of the fungal cell wall [71-74]. There are several types of echinocandins; the caspofungin was the first U.S. FDA-approved echinocandin, and it is commercially available as caspofungin acetate. The next echinocandins added to the list were micafungin and anidulafungin, which were approved in 2005 and 2006, respectively [75,76].

The determination of resistance to echinocandins can be performed phenotypically using the broth microdilution or disc diffusion methods, the Etest method, as well as commercial systems. It can also be done molecularly by detecting mutations in the "hot spots" (HS) regions of FKS1 and FKS2 genes. In addition, the Matrix-Assisted Laser Desorption Ionization Time-of-Flight Mass Spectrometry (MALDI-TOF) technique for echinocandin resistance detection is already in use [77-82]. Two organizations, the European Committee on Antimicrobial Susceptibility Testing (EUCAST) and the Clinical and Laboratory Standards Institute (CLSI), have established reproducible and highly reliable susceptibility broth dilution tests for Candida spp., and echinocandins. These reference methods have shown to be reliable and useful in clinical mycology reference laboratories for determining resistance in clinical isolations [83-85].

Resistance to echinocandins can lead to clinical failures and is conferred by nucleotide substitutions that generate amino acid changes in the catalytic subunit of the target enzyme of echinocandins, the $\beta-1,3$-D-glucan synthase, which is encoded by FKS1, FKS2 and FKS3 genes [86]. The mechanism is highly specific and different from the azole group, because resistance to echinocandins is not affected by multidrug transporters [87]. Mutations in FKS that confer resistance to echinocandins are located in 
2 highly conserved regions of the FKS1 gene known as "hot spot" (HS) that include Phe641-Pro649 and Arg1361 residues and in homologous regions of the FKS2 gene in C. glabrata (Table A1).

For C. albicans, amino acid changes in Ser641 and Ser645 are the most common ones and cause a higher resistance phenotype, while in C. glabrata, amino acid modifications in Ser663 in FKS2, Ser629 in FKS1 and Phe659 in FKS2 are the most common amino acid substitutions [88-91]. Finally, Johnson et al., 2011 reported a third hot-spot region in W695L in FKS1 generated through site-directed mutagenesis in Saccharomyces cerevisiae from an in vitro study, but this mutation has not been observed in clinical isolations [92]. Amino acid substitutions may decrease the sensitivity of glucan synthase, resulting in high minimum inhibitory concentration (MIC) values.

Information on the molecular resistance mechanisms of $C$. auris to different antifungal agents is scarce, and the accuracy of these mechanisms in the different isolated strains is not well defined. $C$. auris escapes from the microbicidal effect of most antifungal groups through different mechanisms, including mutations in ERG3 and ERG11 genes, positive gene regulation of the efflux pump and single nucleotide polymorphism (SNP) in different genome loci [6,27].

As in other Candida species, resistance to echinocandin in C. auris is associated with mutations in HS sites of the FKS1 gene, which encodes the catalytic subunits of the target enzyme $\beta$-1,3-D-glucan synthase [86] (Table A1). Resistance to echinocandins has been reported mainly in C. auris isolates from India and South Africa in studies conducted by Chowdhary et al. 2014, 2018 and Sharma, 2016, in which $2 \%$ of the isolates had a high MIC of $\geq 8 \mathrm{mg} / \mathrm{L}$ (pan-echinocandin resistant phenotype) against caspofungin, micafungin and anidulafungin. On the other hand, Hou et al., 2018 analyzed the HSI of FKS1 in 4 isolations that presented serine in place of phenylalanine in codon 639 (S639F), which is equivalent to the S645 substitution in FKS1 HSI in C. albicans [19,47,62,93]. Also, Berkow et al., 2018 assessed in a drug response test in vivo and did not respond to echinocandin therapy in the invasive candidiasis mouse model [94]. A different amino acid substitution in the same position (S639P) of the HSI was recently reported by Berkow et al., 2018 in C. auris isolates resistant to echinocandin, which corresponds to the S645P substitution in C. albicans, and S629P C. glabrata [94]. The last mutation in HSI associated with equinocandin resistance is S639Y [62].

Due to the increasing prevalence of $C$. auris multidrug resistance, surveillance is recommended in patients infected or colonized with C. auris [55]. The increase in multi-resistant strains to different antifungal groups is a global alarm as it leaves few therapeutic options and becomes a global public health problem.

Recently, the rezafungin (formerly CD101), which is in final evaluation tests (phase 3), has been integrated into this group. This new member is a more stable structural analog of the anidulafungin as it possesses half a choline at the C-5 position of ornithine. It has a prolonged half-life of approximately $130 \mathrm{~h}$, which is very useful from the clinical standpoint for weekly intravenous administrations. However, the EUCAST and CLSI cut-off values are not yet defined $[95,96]$.

There are some reports of the rezafungin behavior against $C$. auris isolates from different countries such as Pakistan, Venezuela, Panama, Colombia, India, South Africa, Israel, and the United States. In vitro activity was very similar for all isolates with average MIC values of $0.25 \mathrm{mg} / \mathrm{L}$. Regarding isolates that had mutations in FKS1 HS1, the observed rezafungin MIC values were slightly lower than the MIC values of anidulafungin and micafungin in most Candida species; however, they were noticeably smaller in C. auris isolates $[6,94,97,98]$.

\section{Alternative Treatment Strategies in C. auris}

The high rate of antifungal resistance of $C$. auris, and its great ability to form biofilms, creates the need to look for alternative treatments for the infections caused by this yeast. Among the alternatives that have been explored are natural peptides, phenolic compounds, nitric oxide in nanoparticles, as well as the reuse of drugs such as miltefosine and iodoquinol [11-17,99]. One of the natural peptides with antimicrobial activity is crotamine, a toxin obtained from the rattlesnake's venom [11]. The antifungal effect of crotamine was evaluated by Dal Mas et al., 2019 in Candida spp. clinical isolates, 
including fluconazole and amphotericin-B-resistant $C$. auris. Crotamine showed a fungicide effect in vitro at a concentration of $40-80 \mu \mathrm{M}$. Based on these results, it has been proposed that the crotamine's chemical structure can serve as a model for the generation of new antifungals against $C$. auris and other multi-resistant Candida species.

Plant essential oils are of great interest, as they contain various phenolic compounds with fungicide activity against Candida species. Among these compounds are eugenol, methyl eugenol, thymol, carvacrol, and farnesol, with carvacrol and farnesol being the most active compounds $[15,17]$. Shaban et al., 2020 conducted in vitro studies, where carvacrol showed a MIC value of $125 \mathrm{mg} / \mathrm{L}$, and its combination with fluconazole, amphotericin $\mathrm{B}$, nystatin and caspofungin produced synergistic and additive effects at $68 \%, 64 \%, 96 \%$, and $28 \%$, respectively. Besides, the combination of carvacrol reduced the MIC values of antifungals [17]. Farnesol has shown significant inhibition of planktonic cell growth in C. auris at concentrations ranging from 0.3 to $62.5 \mathrm{mM}$ within $24 \mathrm{~h}[15,100]$. With regards to the in vivo experiments, daily treatment with $75 \mathrm{mM}$ of farnesol decreased the fungal load in an immunosuppressed murine model with disseminated candidiasis, especially in the case of pre-exposed inoculums to farnesol [15]. Both carvacrol and farnesol inhibit cell adherence and biofilm formation, mitigating Candida spp. virulence $[15,17,100]$. Based on this evidence, phenolic compounds can be said to have an alternative or adjuvant therapeutic potential in conventional treatments to control life-threatening infections caused by C. auris.

Cuminaldehyde is another essential oil component that has also been used to develop eleven azolic compounds (UoST1-11) by replacing the toxic aldehyde group with isopropyl or ter-butyl at the C-4 position of the phenyl ring and the replaced phenyl bonded to the $\mathrm{N}-4$ position of the triazole ring bearing 3-Cl, 4- $\mathrm{Cl}, 4-\mathrm{CH} 3,4-\mathrm{OCH} 3,4-\mathrm{F}, 3-\mathrm{Br}$ or a non-replaced phenyl [13]. Of the eleven compounds, UoST5, 7, 8, and 11 had significant antifungal activity against $C$. auris and other multidrug-resistant pathogens. UoST5 was also formulated in polymeric nanoparticles (NPs) to mitigate their toxicity. With the new formula, UoST5-NPs provided a $25 \%$ release after $24 \mathrm{~h}$, thus maintaining a prolonged activity up to $48 \mathrm{~h}$, without presenting toxicity in low concentrations [13].

On the other hand, nitric oxide (NO), a natural product of the immune system, acts as a broad-spectrum antimicrobial agent. In fungi, the NO has shown efficacy against C. auris $[12,101]$. Cleare et al., 2020 demonstrated the effectiveness of NO nanoparticles (NAC-SNO-np) against six C. auris clinical isolates. This nanoparticle formulation slowly releases $\mathrm{NO}, \mathrm{N}$-acetylcysteine (NAC), and $\mathrm{N}$-acetylcysteine S-nitrosothiol (NAC-SNO), which exhibit antimicrobial activity. The NO released is supplied continuously to the $C$. auris planktonic cells to inhibit their proliferation; it also significantly disrupts the biofilms formation. Based on the later, NAC-SNO-np represents a promising alternative to prophylactic and therapeutic treatments for C. auris infections [12].

A quick and cost-effective alternative to counteract $C$. auris is the reuse of existing medicines for the treatment of other diseases as antifungals. The most representative examples are iodoquinol and miltefosine (MFS) [14,99]. Iodoquinol, a halogenated derivative of quinoline, is used as an intestinal antiparasitic drug, as well as to treat bacterial and fungal skin infections [99]. Iodoquinol has significantly shown in vitro inhibitory activity against $C$. auris planktonic cells; however, its effect on biofilms has been negligible [99]. The MFS, an antineoplastic and antiparasitic drug that, in free form or encapsulated in alginate nanoparticles (MFS-AN) to reduce its gastrointestinal toxicity, has shown fungicide activity ( 2 to $4 \mathrm{mg} / \mathrm{L}$ ) in C. auris clinical isolates. Also, it inhibits the formation of biofilms at a concentration of 0.25 to $4 \mathrm{mg} / \mathrm{L}$. In comparison, at a higher concentration (16 to $32 \mathrm{mg} / \mathrm{L}$ ), it prevents the growth of preformed biofilms [14]. During in vivo trials, treatment with free MFS or MFS-AN has significantly improved the survival and morbidity rates of Galleria mellonella larvae infected by C. auris, which demonstrates that MFS is a promising therapeutic alternative [14].

Finally, with the evidence that nanoencapsulation strategies reduce drug toxicity, Rodriguez et al., 2020 developed micellar systems for the administration of amphotericin B, using amphiphilic block copolymers (ABCs) conjugated with retinol. Amphotericin B encapsulated in polymeric micelles has shown an improvement in antifungal efficiency, with MIC values of $0.93-1.865 \mathrm{mg} / \mathrm{L}$ against $C$. albicans 
and C. auris, compared to the MIC values $\left(3.75 \mathrm{mg} / \mathrm{L}\right.$ ) of Fungizone ${ }^{\circledR}$. Thus, it is possible that infections caused by amphotericin-B-resistant $C$. auris are treated with the same antifungal but encapsulated in polymeric micelles [16].

\section{Conclusions}

Candida auris is considered a global public health problem due to the increase of multi-resistant strains to different antifungal groups, leaving few therapeutic options currently. The possibility has been raised that the $C$. auris genome has adapted to emerge as a resistant pathogen due to the indiscriminate use of broad-spectrum antibiotics and antifungals, as it presently occurs with resistance to triazoles, due to their abuse in marginalized populations. At the same time, the study of molecular resistance mechanisms to different kinds of antifungals has become complicated due to the genetic variation between $C$. auris clades. As it is known, resistance to polyenes varies depending on the region where the strain is isolated; likewise, reports of $C$. auris strains resistant to echinocandins have been made in India and South Africa. For now, the knowledge of the molecular resistance mechanisms of $C$. auris is scarce; however, this resistance can occur through mutations in the ERG2, ERG3, ERG6, ERG11, and FKS1 genes, positive regulation of the efflux pump genes and single nucleotide polymorphism (SNP) in different loci of its genome. The use of polyenes for the treatment of $C$. auris can be enhanced by using other antifungals such as 5-FC. Although 5-FC doesn't constitute the treatment of choice for these infections, it is a good option if given in combination with polyenes, echinocandins, or azoles. $C$. auris is a widely spread organism that causes a high mortality rate; however, this species has been little studied. It is imperative to explore in-depth the resistance mechanisms for this emerging yeast, as well as research aimed at other molecular factors that may be involved in tolerance and resistance to antifungals to find new and better treatment options.

It is important to note that the high rate of antifungal resistance of $C$. auris has prompted the search for alternative treatment strategies; however, it is necessary to conduct thorough research before they can be applied in patients. We thank Shiftext for the translation.

Author Contributions: M.G.F.-D.-L. and E.M.-H. wrote the manuscript and designed the study, contributing equally to the accomplishment of the work; R.H.-C., T.V.-G. and L.C.-O. contribute to the writing of the manuscript; M.G.F.-D.-L., E.M.-H., R.A. planned, extracted data, wrote, and critically reviewed the manuscript; E.M.-H., A.B., G.A.-A. planned, wrote, and critically reviewed the manuscript. All authors have read and agreed to the published version of the manuscript.

Funding: This research received no external funding.

Acknowledgments: María Esther Conde Cuevas, Itzel Hayde García-Coronel and Víctor Manuel Espinosa-Hernández from the "Instituto Politécnico Nacional (IPN)" for their assistance in the editing the manuscript.

Conflicts of Interest: The authors declare no conflict of interest.

\section{Appendix A}

Table A1. Main resistance mechanisms of action to polyene, triazoles and echinocandins in C. auris.

\begin{tabular}{ccll}
\hline Antifungal & $\begin{array}{c}\text { Genes Associated with } \\
\text { Resistance }\end{array}$ & \multicolumn{1}{c}{ Effect on C. auris } & References \\
\hline & & - & Ergosterol biosynthesis path \\
\multirow{3}{*}{ Polyenes } & $E R G 1, E R G 2, E R G 3, E R G 5$, & - & Overexpression of genes \\
& $E R G 6, E R G 11, E R G 13$ & - & Alterations in ergosterol composition \\
& - & Decrease or absence in ergosterol levels & \\
& &
\end{tabular}


Table A1. Cont.

\begin{tabular}{|c|c|c|c|}
\hline Antifungal & $\begin{array}{l}\text { Genes Associated with } \\
\text { Resistance }\end{array}$ & Effect on C. auris & References \\
\hline Triazoles & ERG11 & $\begin{array}{l}\text { - Mutations that alter the shape of the } \\
\text { lanosterol } 14-\alpha \text { its affinity with triazole } \\
\text { - Overexpression of the gene } \\
\text { - Duplications on the chromosome containing } \\
\text { the gene. }\end{array}$ & {$[6,19,24,32,39,55]$} \\
\hline Triazoles & HSP9O & $\begin{array}{ll}- & \text { Promotes cellular response to stress. } \\
\text { - } & \text { Regulates signaling on the cell wall. } \\
\text { - } & \text { Involved in morphogenesis or the fungus. } \\
\text { - } & \text { Involved in fluconazole tolerance }\end{array}$ & [59] \\
\hline Echinocandins & FKS1 & $\begin{array}{ll}\text { - } & \text { Changes in amino acids in the catalytic } \\
\text { subunit of the } \beta-1,3-\mathrm{D}-\text { glucan synthase } \\
\text { - } & \text { Mutation in HSI } \\
\text { - } & \text { Presence of serine in place of phenylalanine } \\
\text { in S639F } \\
\text { - } & \text { Substitution of amino acids in S639P } \\
\text { - } & \text { Mutation in HSI in S639Y }\end{array}$ & {$[19,47,62,86,93]$} \\
\hline Polyenes & Efflux pumps & $\begin{array}{l}\text { Identification of orthologous genes in } \mathrm{ABC} \\
\text { and MFS-type efflux pumps }\end{array}$ & {$[23,24,42,46]$} \\
\hline Triazoles & Efflux pumps & $\begin{array}{l}\text { Transcriptional overexpression and } \\
\text { overregulation of CDR1. } \\
\text { - Resistant strains genome present multiple } \\
\text { genes for ABC transporters }\end{array}$ & {$[26,32,39,56-58]$} \\
\hline Polyenes & $\begin{array}{l}\text { OPT1, CSA1, MET15, ARG1, } \\
\text { MVD, SIT1, PGA7, RBT }\end{array}$ & $\begin{array}{ll}\text { - } & \text { Ergosterol biosynthesis path } \\
\text { - } & \text { Intrinsic transcription of } \\
\text { multidrug transporters } \\
\text { - } \quad \text { Overexpression of genes in } \\
\text { transcriptional response } \\
\text { - } \quad \text { Increased transcription in CDR4a }\end{array}$ & [39] \\
\hline Polyenes & FLO8 & $\begin{array}{l}\text { Mutation in transcription factor for } \\
\text { biofilm formation } \\
\text { - Single-nucleotide polymorphism }\end{array}$ & [42] \\
\hline 5-FC & FUR1 & $\begin{array}{l}\text { - Mutation at the F211I position causes } \\
\text { phenylalanine substitution with isoleucine }\end{array}$ & [8] \\
\hline
\end{tabular}

\section{References}

1. Chybowska, A.D.; Childers, D.S.; Farrer, R.A. Nine Things Genomics Can Tell Us About Candida auris. Front. Genet 2020, 11, 351. [CrossRef] [PubMed]

2. Sarma, S.; Upadhyay, S. Current perspective on emergence, diagnosis and drug resistance in Candida auris. Infect. Drug Resist. 2017, 10, 155-165. [CrossRef]

3. Parra-Giraldo, C.M.; Valderrama, S.L.; Cortes-Fraile, G.; Garzón, J.R.; Ariza, B.E.; Morio, F.; Linares-Linares, M.Y.; Ceballos-Garzón, A.; de la Hoz, A.; Hernández, C.; et al. First report of sporadic cases of Candida auris in Colombia. Int. J. Infect. Dis. 2018, 69, 63-67. [CrossRef] [PubMed]

4. Calvo, B.; Melo, A.S.; Perozo-Mena, A.; Hernández, M.; Francisco, E.C.; Hagen, F.; Meis, J.F.; Lopes Colombo, A. First report of Candida auris in America: Clinical and microbiological aspects of 18 episodes of candidemia. J. Infect. 2016, 73, 369-374. [CrossRef] [PubMed]

5. Chow, N.A.; Muñoz, J.F.; Gade, L.; Berkow, E.L.; Li, X.; Welsh, R.M.; Forsberg, K.; Lockhart, S.R.; Adam, R.; Alanio, A.; et al. Tracing the evolutionary history and global expansion of Candida auris using population genomic analyses. mBio 2020, 11, e03364-19. [CrossRef] [PubMed]

6. Lockhart, S.R.; Etienne, K.A.; Vallabhaneni, S.; Farooqi, J.; Chowdhary, A.; Govender, N.P.; Lopes Colombo, A.; Calvo, B.; Cuomo, C.A.; Desjardins, C.A. Simultaneous emergence of multidrug resistant Candida auris on 3 continents confirmed by whole-genome sequencing and epidemiological analyses. Clin. Infect. Dis. 2017, 64, 134-140. [CrossRef] 
7. Escandón, P.; Chow, N.A.; Caceres, D.H.; Gade, L.; Berkow, E.L.; Armstrong, P.; Rivera, S.; Misas, E.; Duarte, C.; Moulton-Meissner, H.; et al. Molecular Epidemiology of Candida auris in Colombia Reveals a Highly Related, Countrywide Colonization with Regional Patterns in Amphotericin B Resistance. Clin. Infect. Dis. 2019, 68, 15-21. [CrossRef]

8. Rhodes, J.; Abdolrasouli, A.; Farrer, R.A.; Cuomo, C.A.; Aanensen, D.M.; Armstrong-James, D.; Fisher, M.C.; Schelenz, S. Genomic epidemiology of the UK outbreak of the emerging human fungal pathogen Candida auris. Emerg. Microbes Infect. 2018, 7, 43. [CrossRef]

9. Chow, N.O.; De Groot, T.; Badali, H.; Abastabar, M.; Chiller, T.M.; Meis, J.F. Potential fifth clade of Candida auris, Iran, 2018. Emerg. Infect. Dis. 2019, 25, 1780-1781. [CrossRef]

10. Kordalewska, M.; Lee, A.; Park, S.; Berrio, I.; Chowdhary, A.; Zhao, Y.; Perlin, D.S. Understanding echinocandin resistance in the emerging pathogen Candida auris. Antimicrob. Agents Chemother. 2018, 62, e00238-18. [CrossRef]

11. Dal Mas, C.; Rossato, L.; Shimizu, T.; Oliveira, E.B.; da Silva Junior, P.I.; Meis, J.F.; Lopes Colombo, A.; Hayashi, M.A.F. Effects of the natural peptide crotamine from a South American rattlesnake on Candida auris, an emergent multidrug antifungal resistant human pathogen. Biomolecules 2019, 9, 205. [CrossRef] [PubMed]

12. Cleare, L.G.; Li, K.L.; Abuzeid, W.M.; Nacharaju, P.; Friedman, J.M.; Nosanchuk, J.D. NO Candida auris: Nitric oxide in nanotherapeutics to combat emerging fungal pathogen Candida auris. J. Fungi 2020, 6, 85. [CrossRef]

13. Hamdy, R.; Fayed, B.; Hamoda, A.M.; Rawas-Qalaji, M.; Haider, M.; Soliman, S.S.M. Essential oil-based design and development of novel anti-Candida azoles formulation. Molecules 2020, 25, 1463. [CrossRef] [PubMed]

14. Lopes Barreto, T.; Rossato, L.; Duarte de Freitas, A.L.; Meis, J.F.; Biagini Lopes, L.; Lopes Colombo, A.; Ishida, K. Miltefosine as an alternative strategy in the treatment of the emerging fungus Candida auris. Int. J. Antimicrob. Agents 2020, 56, 106049. [CrossRef] [PubMed]

15. Nagy, F.; Vitális, E.; Jakab, Á.; Borman, A.M.; Forgács, L.; Tóth, Z.; Majoros, L.; Kovács, R. In vitro and in vivo effect of exogenous farnesol exposure against Candida auris. Front. Microbiol. 2020, 11, 957. [CrossRef]

16. Rodriguez, Y.J.; Quejada, L.F.; Villamil, J.C.; Baena, Y.; Parra-Giraldo, C.M.; Perez, L.D. Development of amphotericin B micellar formulations based on copolymers of poly (ethylene glycol) and poly("'-caprolactone) conjugated with retinol. Pharmaceutics 2020, 12, 196. [CrossRef]

17. Shaban, S.; Patel, M.; Ahmad, A. Improved efficacy of antifungal drugs in combination with monoterpene phenols against Candida auris. Sci. Rep. 2020, 10, 1162. [CrossRef]

18. Dalhoff, A. Does the use of antifungal agents in agriculture and in food foster polyene-resistance development? A reason for concern. Integr. Med. Res. 2017, 13, 40-48. [CrossRef]

19. Chowdhary, A.; Prakash, A.; Sharma, C.; Kordalewska, M.; Kumar, A.; Sarma, S.; Tarai, B.; Singh, A.; Upadhyaya, G.; Upadhyay, S.; et al. A multicentre study of antifungal susceptibility patterns among 350 Candida auris isolates (2009-17) in India: Role of the ERG11 and FKS1 genes in azole and echinocandin resistance. J. Antimicrob. Chemother. 2018, 73, 891-899. [CrossRef]

20. Montoya, M.C.; Moye-Rowley, W.S.; Krysan, D.J. Candida auris: The Canary in the Mine of Antifungal Drug Resistance. ACS Infect. Dis. 2019, 5, 1487-1492. [CrossRef]

21. Iguchi, S.; Itakura, Y.; Yoshida, A.; Kamada, K.; Mizushima, R.; Arai, Y.; Uzawa, Y.; Kikuchi, K. Candida auris: A pathogen difficult to identify, treat, and eradicate and its characteristics in Japanese strains. J. Infect. Chemother. 2019, 25, 743-749. [CrossRef] [PubMed]

22. Perlin, D.S.; Rautemaa-Richardson, R.; Alastruey-Izquierdo, A. The global problem of antifungal resistance: Prevalence, mechanisms, and management. Lancet Infect. Dis. 2017, 17, e383-e392. [CrossRef]

23. Moreno, A.; Banerjee, A.; Prasad, R.; Falson, P. PDR-like ABC systems in pathogenic fungi. Res. Microbiol. 2019, 170, 417-425. [CrossRef] [PubMed]

24. Chatterjee, S.; Alampalli, S.V.; Nageshan, R.K.; Chettiar, S.T.; Joshi, S.; Tatu, U.S. Draft genome of a commonly misdiagnosed multidrug resistant pathogen Candida auris. BMC Genom. 2015, 16, 686. [CrossRef]

25. Arendrup, M.C.; Prakash, A.; Meletiadis, J.; Sharma, C.; Chowdhary, A. Comparison of EUCAST and CLSI Reference Microdilution MICs of Eight Antifungal Compounds for Candida auris and Associated Tentative Epidemiological Cutoff Values. Antimicrob. Agents Chemother. 2017, 61, e00485-17. [CrossRef]

26. Ostrowsky, B.; Greenko, J.; Adams, E.; Quinn, M.; O’Brien, B.; Chaturvedi, V.; Berkow, E.; Vallabhaneni, S.; Forsberg, K.; Chaturvedi, S.; et al. Candida auris Isolates Resistant to Three Classes of Antifungal Medications-New York, 2019. MMWR Morb. Mortal Wkly Rep. 2020, 69, 6-9. [CrossRef] 
27. Ademe, M.; Girma, F. Candida auris: From Multidrug resistance to pan-resistant strains. Infect. Drug. Resist. 2020, 13, 1287-1294. [CrossRef]

28. Vallabhaneni, S.; Kallen, A.; Tsay, S.; Chow, N.; Welsh, R.; Kerins, J.; Kemble, S.K.; Pacilli, M.; Black, S.R.; Landon, E.; et al. Investigation of the First Seven Reported Cases of Candida auris, a Globally Emerging Invasive, Multidrug-Resistant Fungus-United States, May 2013-August 2016. Am. J. Transpl. 2017, 17, 296-299. [CrossRef]

29. Osei Sekyere, J. Candida auris: A systematic review and meta-analysis of current updates on an emerging multidrug-resistant pathogen. Miocrobiologyopen 2018, 7, e00578. [CrossRef]

30. Arendrup, M.C.; Patterson, T.F. Multidrug-Resistant Candida: Epidemiology, Molecular Mechanisms, and Treatment. J. Infect. Dis. 2017, 216 (Suppl. 3), S445-S451. [CrossRef]

31. Khan, Z.; Ahmad, S.; Al-Sweih, N.; Joseph, L.; Alfouzan, W.; Asadzadeh, M. Increasing prevalence, molecular characterization and antifungal drug susceptibility of serial Candida auris isolates in Kuwait. PLoS ONE 2018, 13, e0195743. [CrossRef] [PubMed]

32. Lockhart, S.R. Candida auris and multidrug resistance: Defining the new normal. Fungal Genet. Biol. 2019, 131, 103243. [CrossRef] [PubMed]

33. Tan, Y.E.; Teo, J.Q.; Rahman, N.B.A.; Ng, O.T.; Kalisvar, M.; Tan, A.L.; Koh, T.H.; Ong, R.T.H. Candida auris in Singapore: Genomic epidemiology, antifungal drug resistance, and identification using the updated 8.01 VITEK ${ }^{\circledR} 2$ system. Int. J. Antimicrob. Agents 2019, 54, 709-715. [CrossRef] [PubMed]

34. Bhattacharya, S.; Sae-Tia, S.; Fries, B.C. Candidiasis and mechanisms of antifungal resistance. Antibiotics 2020, 9, 312. [CrossRef]

35. Ahmad, S.; Joseph, L.; Parker, J.E.; Asadzadeh, M.; Kelly, S.L.; Meis, J.F.; Khan, Z. ERG6 and ERG2 Are Major Targets Conferring Reduced Susceptibility to Amphotericin B in Clinical Candida glabrata Isolates in Kuwait. Antimicrob. Agents Chemother. 2019, 63, e01900-18. [CrossRef] [PubMed]

36. Kean, R.; Ramage, G. Combined Antifungal Resistance and Biofilm Tolerance: The Global Threat of Candida auris. mSphere 2019, 4, e00458-19. [CrossRef]

37. Colombo, A.L.; Almeida Junior, J.N.; Guinea, J. Emerging multidrug-resistant Candida species. Curr. Opin. Infect. Dis. 2017, 30, 528-538. [CrossRef]

38. Chaabane, F.; Graf, A.; Jequier, L.; Coste, A.T. Review on Antifungal Resistance Mechanisms in the Emerging Pathogen Candida auris. Front. Microbiol. 2019, 10, 1-8. [CrossRef]

39. Muñoz, J.F.; Gade, L.; Chow, N.A.; Loparev, V.N.; Juieng, P.; Berkow, E.L.; Farrer, R.A.; Litvintseva, A.P.; Cuomo, C.A. Genomic insights into multidrug-resistance, mating and virulence in Candida auris and related emerging species. Nat. Commun. 2018, 9, 5346. [CrossRef]

40. Kordalewska, M.; Perlin, D.S. Identification of drug resistant Candida auris. Front. Microbiol. 2019, 10, 1918. [CrossRef]

41. Escandón, P.; Cáceres, D.H.; Espinosa-Bode, A.; Rivera, S.; Armstrong, P.; Vallabhaneni, S.; Berkow, E.L.; Lockhart, S.R.; Chiller, T.; Jackson, R.; et al. Notes from the Field: Surveillance for Candida auris—Colombia, September 2016-May 2017. MMWR Morb. Mortal Wkly. Rep. 2018, 67, 459-460. [CrossRef] [PubMed]

42. Misas, E.; Escandón, P.; McEwen, J.G.; Clay, O.K. The LUFS domain, its transcriptional regulator proteins, and drug resistance in the fungal pathogen Candida auris. Protein Sci. 2019, 28, 2024-2029. [CrossRef] [PubMed]

43. Romera, D.; Aguilera-Correa, J.; Gadea, I.; Viñuela-Sandoval, L.; García-Rodríguez, J.; Esteban, J. Candida auris: A comparison between planktonic and biofilm susceptibility to antifungal drugs. J. Med. Microbiol. 2019, 68, 1353-1358. [CrossRef] [PubMed]

44. ElBaradei, A. A decade after the emergence of Candida auris: What do we know? Eur. J. Clin. Microbiol. Infect. Dis. 2020. [CrossRef] [PubMed]

45. Sherry, L.; Ramage, G.; Kean, R.; Borman, A.; Johnson, E.M.; Richardson, M.D.; Rautemaa-Richardson, R. Biofilm- Forming Capability of Highly Virulent, Multidrug-Resistant Candida auris. Emerg. Infect. Dis. 2017, 23, 328-331. [CrossRef]

46. Ben-Ami, R.; Berman, J.; Novikov, A.; Bash, E.; Shachor-Meyouhas, Y.; Zakin, S.; Maor, Y.; Tarabia, J.; Schechner, V.; Adler, A.; et al. Multidrug-Resistant Candida haemulonii and C. auris, Tel Aviv, Israel. Emerg. Infect. Dis. 2017, 23, 195-203. [CrossRef] [PubMed]

47. Sharma, C.; Kumar, N.; Pandey, R.; Meis, J.F.; Chowdhary, A. Whole genome sequencing of emerging multidrug resistant Candida auris isolates in India demonstrates low genetic variation. New Microbes New Infect. 2016, 13, 77-82. [CrossRef] 
48. Allevato, J.M.A.; Negroni, R.; Galimberti, R. Antifúngicos ayer, hoy y mañana. Act. Terap. Dermatol. 2007, 30, 8-19.

49. Sádaba, B.; García-Quetglas, E.; Azanza, J.R. Relación entre estructura y función de los azoles. Rev. Esp. Quimioterap. 2004, 17, 71-78.

50. Lv, X.; Pan, L.; Wang, J.; Lu, L.; Yan, W.; Zhu, Y.; Xu, Y.; Guo, M.; Zhuang, S. Effects of triazole fungicides on androgenic disruption and CYP3A4 enzyme activity. Environ. Pol. 2016, 30, 1-9. [CrossRef]

51. Catalán, M.; Montejo, J.C. Antifúngicos sistémicos. Farmacodinamia y farmacocinética. Rev. Iberoam. Micol. 2006, 23, 39-40. [CrossRef]

52. Hoffman, H.L.; Ernst, E.J.; Klepser, M.E. Novel triazole antifungal agents. Exp. Opin. Investig. Drugs 2000, 9, 593-605. [CrossRef]

53. Gómez, J.; García-Vázquez, E.; Hernández, A.; Espinosa, C.; Ruíz, J. Candidemias nosocomiales: Nuevos retos de un problema emergente. Rev. Esp. Quimioterap. 2010, 23, 158-168.

54. Chowdhary, A.; Sharma, C.; Mais, J.F. Candida auris: A rapidly emerging cause of hospital-acquired multidrug-resistant fungal infections globally. PLoS Pthog. 2017, 13, e1006290. [CrossRef]

55. Forsberg, K.; Woodworth, K.; Walters, M.; Berkow, E.L.; Jackson, B.; Chiller, T.; Vallabhaneni, S. Candida auris: The recent emergence of a multidrug-resistant fungal pathogen. Med. Mycol. 2019, 57, 1-12. [CrossRef]

56. Battacharya, S.; Holowka, T.; Orner, E.P.; Fries, B.C. Gene duplication associated with increased fluconazole tolerance in Candida auris cells of advanced generational age. Sci. Rep. 2019, 9, 5052. [CrossRef]

57. Kean, R.; Delaney, C.; Sherry, L.; Borman, A.; Johnson, E.M.; Richardson, M.D.; Rautemaa-Richardson, R.; Williams, C.; Ramage, G. Transcriptome Assembly and Profiling of Candida auris Reveals Novel Insights into Biofilm-Mediated Resistance. mSphere 2018, 3, e00334-18. [CrossRef]

58. Rybak, J.M.; Doorley, L.A.; Nishimoto, A.T.; Barker, K.S.; Palmer, G.E.; Rogers, P.D. Abrogation of Triazole Resistance upon Deletion of CDR1 in a Clinical Isolate of Candida auris. Antimicrob. Agents Chemother. 2019, 63, e00057-19. [CrossRef] [PubMed]

59. Kim, S.H.; Iyer, K.R.; Pardeshi, L.; Muñoz, J.F.; Robbins, N.; Cuomo, C.A.; Wong, K.H.; Cowena, L.E. Genetic Analysis of Candida auris Implicates Hsp90 in Morphogenesis and Azole Tolerance and Cdr1 in Azole Resistance. mBio 2019, 10, e02529-18. [CrossRef] [PubMed]

60. Carmona, E.M.; Limper, A.H. Overview of treatment approaches for fungal infections. Clin. Chest Med. 2017, 38, 393-402. [CrossRef] [PubMed]

61. Schelenz, S.; Hagen, F.; Rhodes, J.L.; Abdolrasouli, A.; Chowdhary, A.; Hall, A.; Ryan, L.; Shackleton, J.; Trimlett, R.; Meis, J.F.; et al. First hospital outbreak of the globally emerging Candida auris in a European hospital. Antimicrob. Resist. Infect. Control 2016, 5, 35. [CrossRef] [PubMed]

62. Chowdhary, A.; Anil-Kumar, V.; Sharma, C.; Prakash, A.; Agarwal, K.; Babu, R.; Dinesh, K.R.; Karim, S.; Singh, S.K.; Hagen, F.; et al. Multidrug-resistant endemic clonal strain of Candida auris in India. Eur. J. Clin. Microbiol. Infect. Dis. 2014, 33, 919-926. [CrossRef] [PubMed]

63. Kathuria, S.; Singh, P.K.; Sharma, C.; Prakash, A.; Masih, A.; Kumar, A.; Meis, J.F.; Chowdhary, A. Multidrug-resistant Candida auris misidentified as Candida haemulonii: Characterization by matrix-assisted laser desorption ionization-time of flight mass spectrometry and DNA sequencing and its antifungal susceptibility profile variability by Vitek 2, CLSI broth microdilution, and Etest method. J. Clin. Microbiol. 2015, 53, 1823-1830. [CrossRef] [PubMed]

64. O'Brien, B.; Chaturvedi, S.; Chaturvedi, V. In vitro evaluation of antifungal drug combinations against multidrug-resistant Candida auris isolates from New York outbreak. Antimicrob. Agents Chemother. 2020. [CrossRef] [PubMed]

65. Charlier, C.; El-Sissy, C.; Bachelier-Bassi, S.; Scemla, A.; Quesne, G.; Sitterle, E.; Legendre, C.; Lortholary, O.; Bougnoux, M.E. Acquired flucytosine resistance during combination therapy with caspofungin and flucytosine for Candida glabrata cystitis. Antimicrob. Agents Chemother. 2016, 60, 662-665. [CrossRef] [PubMed]

66. Costa, C.; Ponte, A.; Pais, P.; Santos, R.; Cavalheiro, M.; Yaguchi, T.; Chibana, H.; Cacho Texeira, M. New mechanisms of flucytosine resistance in C. glabrata unveiled by a chemogenomics analysis in S. cerevisiae. PLoS ONE 2015, 10, e0135110. [CrossRef]

67. Noël, T.; Francois, F.; Paumard, P.; Chastin, C.; Brethes, D.; Villard, J. Flucytosine-fluconazole cross-resistance in purine-cytosine permease deficient Candida lusitaniae clinical isolates: Indirect evidence of a fluconazole uptake transporter. Antimicrob. Agents Chemother. 2003, 47, 1275-1284. [CrossRef] 
68. Dodgson, A.R.; Dodgson, K.J.; Pujol, C.; Pfaller, M.A.; Soll, D.R. Clade-specific flucytosine resistance is due to a single nucleotide change in the FUR1 gene of Candida albicans. Antimicrob. Agents Chemother. 2004, 48, 2223-2227. [CrossRef]

69. Papon, N.; Noel, T.; Florent, M.; Gibot-Leclerc, S.; Jean, D.; Christiane, C.; Villard, J.; Chapeland-Leclerc, F. Molecular mechanism of flucytosine resistance in Candida lusitaniae: Contribution of the FCY2, FCY1, and FUR1 genes to 5-fluorouracil and fluconazole cross-resistance. Antimicrob. Agents Chemother. 2007, 51, 369-371. [CrossRef]

70. Bidaud, A.L.; Botterel, F.; Chowdhary, A.; Dannaoui, E. In vitro antifungal combination of flucytosine with amphotericin B, voriconazole, or micafungin against Candida auris shows no antagonism. Antimicrob. Agents Chemother. 2019, 63, e01393-19. [CrossRef]

71. Zhu, Y.; O’Brien, B.; Leach, L.; Clarke, A.; Bates, M.; Adams, E.; Ostrowsky, B.; Quinn, M.; Dufort, E.; Southwick, K.; et al. Laboratory analysis of an outbreak of Candida auris in New York from 2016 to 2018 : Impact and lessons learned. J. Clin. Microbiol. 2020, 58, e01503-19. [CrossRef]

72. Chandrasekar, P.; Sobel, J. Micafungin: A new echinocandin. Clin. Infect. Dis. 2006, 42, 1171-1178. [CrossRef] [PubMed]

73. Davis, S.L.; Vazquez, J.A. Anidulafungin: An evidence-based review of its use in invasive fungal infections. Core Evid. 2008, 2, 241-249.

74. Kurtz, M.B.; Heath, I.B.; Marrinan, J.; Dreikorn, S.; Onishi, J.; Douglas, C. Morphological effects of lipopeptides against Aspergillus fumigatus correlate with activities against (1,3)-beta-D-glucan synthases. Antimicrob. Agents Chemother. 1994, 38, 1480-1489. [CrossRef] [PubMed]

75. Chen, S.C.; Slavin, M.A.; Sorrell, T.C. Echinocandin antifungal drugs in fungal infections: A comparison. Drugs 2011, 71, 11-41. [CrossRef] [PubMed]

76. Denning, D. Echinocandins: A new class of antifungal. J. Antimicrob. Chemother. 2002, 6, 889-891. [CrossRef] [PubMed]

77. Guinea, J.; Zaragoza, Ó.; Escribano, P.; Martín-Mazuelos, E.; Pemán, J.; Sánchez-Reus, F.; Cuenca-Estrella, M. Molecular identification and antifungal susceptibility of yeast isolates causing fungemia collected in a population-based study in Spain in 2010 and 2011. Antimicrob. Agents Chemother. 2014, 58, 1529-1537. [CrossRef]

78. Dudiuk, C.; Gamarra, S.; Leonardeli, F.; Jimenez-Ortigosa, C.; Vitale, R.G.; Afeltra, J.; Perlin, D.S.; Garcia-Effron, G. Set of classical PCRs for detection of mutations in Candida glabrata FKS genes linked with echinocandin resistance. J. Clin. Microbiol. 2014, 52, 2609-2614. [CrossRef]

79. Pham, C.D.; Bolden, C.B.; Kuykendall, R.J.; Lockhart, S.R. Development of a Luminex-based multiplex assay for detection of mutations conferring resistance to Echinocandins in Candida glabrata. J. Clin. Microbiol. 2014, 52, 790-795. [CrossRef]

80. Vella, A.; De Carolis, E.; Vaccaro, L.; Posteraro, P.; Perlin, D.S.; Kostrzewa, M.; Posteraro, B.; Sanguinetti, M. Rapid antifungal susceptibility testing by matrix-assisted laser desorption ionization-time of flight mass spectrometry analysis. J. Clin. Microbiol. 2013, 51, 2964-2969. [CrossRef]

81. Arendrup, M.C.; Garcia-Effron, G.; Lass-Flörl, C.; Lopez, A.G.; Rodriguez-Tudela, J.L.; Cuenca-Estrella, M.; Perlin, D.S. Echinocandin susceptibility testing of Candida species: Comparison of EUCAST EDef 7.1, CLSI M27-A3, Etest, disk diffusion, and agar dilution methods with RPMI and isosensitest media. Antimicrob. Agents Chemother. 2010, 54, 426-439. [CrossRef] [PubMed]

82. Pfaller, M.A.; Chaturvedi, V.; Diekema, D.J.; Ghannoum, M.A.; Holliday, N.M.; Killian, S.B.; Knapp, C.C.; Messer, S.A.; Miskou, A.; Ramani, R. Comparison of the Sensititre YeastOne colorimetric antifungal panel with CLSI microdilution for antifungal susceptibility testing of the echinocandins against Candida spp., using new clinical breakpoints and epidemiological cutoff values. Diagn. Microbiol. Infect. Dis. 2012, 73, 365-368. [CrossRef] [PubMed]

83. Clinical and Laboratory Standards Institute. Reference Method for Broth Dilution Antifungal Susceptibility Testing of Yeasts; Fourth Informational Supplement M27-S4; Clinical and Laboratory Standards Institute: Wayne, PA, USA, 2012.

84. Leclercq, R.; Cantón, R.; Brown, D.F.; Giske, C.G.; Heisig, P.; MacGowan, A.P.; Mouton, W.; Nordmann, P.; Rodloff, A.C.; Rossolini, G.M.; et al. EUCAST expert rules in antimicrobial susceptibility testing. Clin. Microbiol. Infect. 2013, 19, 141-160. [CrossRef] [PubMed] 
85. Shields, R.K.; Nguyen, M.H.; Clancy, C.J. Clinical perspectives on echinocandin resistance among Candida species. Curr. Opin. Infect. Dis. 2015, 28, 514-522. [CrossRef] [PubMed]

86. Perlin, D.S. Echinocandin Resistance in Candida. Clin. Infect. Dis. 2015, 61, S612-S617. [CrossRef]

87. Niimi, K.; Maki, K.; Ikeda, F.; Holmes, A.R.; Lamping, E.; Niimi, M.; Monk, B.C.; Cannon, R.D. Overexpression of Candida albicans CDR1, CDR2, or MDR1 does not produce significant changes in echinocandin susceptibility. Antimicrob. Agents Chemother. 2006, 50, 1148-1155. [CrossRef]

88. Garcia-Effron, G.; Park, S.; Perlin, D.S. Correlating echinocandin MIC and kinetic inhibition of fks1 mutant glucan synthases for Candida albicans: Implications for interpretive breakpoints. Antimicrob. Agents Chemother. 2009, 53, 112-122. [CrossRef]

89. Katiyar, S.K.; Edlind, T.D. Role for Fks1 in the intrinsic echinocandin resistance of Fusarium solani as evidenced by hybrid expression in Saccharomyces cerevisiae. Antimicrob. Agents Chemother. 2009, 53, 1772-1778. [CrossRef]

90. Park, S.; Kelly, R.; Kahn, J.N.; Robles, J.; Hsu, M.J.; Register, E.; Li, W.; Vyas, V.; Fan, H.; Abruzzo, G.; et al. Specific substitutions in the echinocandin target Fks1p account for reduced susceptibility of rare laboratory and clinical Candida sp. isolates. Antimicrob. Agents Chemother. 2005, 49, 3264-3273. [CrossRef]

91. Garcia-Effron, G.; Lee, S.; Park, S.; Cleary, J.D.; Perlin, D.S. Effect of Candida glabrata FKS1 and FKS2 mutations on echinocandin sensitivity and kinetics of 1,3-beta-D-glucan synthase: Implication for the existing susceptibility breakpoint. Antimicrob. Agents Chemother. 2009, 53, 3690-3699. [CrossRef]

92. Johnson, M.E.; Katiyar, S.K.; Edlind, T.D. New Fks hot spot for acquired echinocandin resistance in Saccharomyces cerevisiae and its contribution to intrinsic resistance of Scedosporium species. Antimicrob. Agents Chemother. 2011, 55, 3774-3781. [CrossRef]

93. Hou, X.; Lee, A.; Jiménez-Ortigosa, C.; Kordalewska, M.; Perlin, D.S.; Zhao, Y. Rapid detection of ERG11-associated azole resistance and FKS-associated echinocandin resistance in Candida auris. Antimicrob. Agents Chemother. 2018, 63, e01811-18. [CrossRef] [PubMed]

94. Berkow, E.L.; Lockhart, S.R. Activity of CD101, a long-acting echinocandin, against clinical isolates of Candida auris. Diagn. Microbiol. Infect. Dis. 2018, 90, 196-197. [CrossRef] [PubMed]

95. Sandison, T.; Ong, V.; Lee, J.; Thye, D. Safety and pharmacokinetics of CD101 IV, a novel echinocandin, in healthy adults. Antimicrob. Agents Chemother. 2017, 61, e01627-16. [CrossRef] [PubMed]

96. James, K.D.; Laudeman, C.P.; Malkar, N.B.; Krishnan, R.; Polowy, K. Structure-Activity Relationships of a series of echinocandins and the discovery of CD101, a highly stable and soluble echinocandin with distinctive pharmacokinetic properties. Antimicrob. Agents Chemother. 2017, 61, e01541-16. [CrossRef]

97. Helleberg, M.; Jørgensen, K.M.; Hare, R.K.; Datcu, R.; Chowdhary, A.; Arendrup, M.C. Rezafungin in vitro activity against contemporary nordic clinical Candida isolates and Candida auris determined by the EUCAST reference method. Antimicrob. Agents Chemother. 2020, 64, e02438-19. [CrossRef]

98. Tóth, Z.; Forgács, L.; Locke, J.B.; Kardos, G.; Nagy, F.; Kovács, R.; Szekely, A.; Borman, A.M.; Majoros, L. In vitro activity of rezafungin against common and rare Candida species and Saccharomyces cerevisiae. J. Antimicrob. Chemother. 2019, 74, 3505-3510. [CrossRef]

99. Wall, G.; Herrera, N.; Lopez-Ribot, J.L. Repositionable compounds with antifungal activity against multidrug resistant Candida auris identified in the medicines for Malaria Venture's Pathogen Box. J. Fungi 2019, 5, 92. [CrossRef]

100. Srivastava, V.; Ahmad, A. Abrogation of pathogenic attributes in drug resistant Candida auris strains by farnesol. PLOS ONE 2020, 15, e0233102. [CrossRef]

101. Vargas-Cruz, N.; Reitzel, R.A.; Rosenblatt, J.; Chaftari, A.-M.; Dib, R.W.; Hachem, R.; Kontoyiannis, D.P.; Raad, I.I. Nitroglycerin-citrate-ethanol catheter lock solution is highly efective for in vitro eradication of Candida auris biofilm. Antimicrob. Agents Chemother. 2019, 63, 63. [CrossRef]

(C) 2020 by the authors. Licensee MDPI, Basel, Switzerland. This article is an open access article distributed under the terms and conditions of the Creative Commons Attribution (CC BY) license (http://creativecommons.org/licenses/by/4.0/). 